\title{
Faroese Language
}

National Cancer Institute

\section{Source}

National Cancer Institute. Faroese Language. NCI Thesaurus. Code C153915.

An Indo-European, North Germanic language spoken mainly on the Faroe Islands and parts of Denmark. 